\title{
The Impact of Value-Belief-Norm Theory and Technology Acceptance Model on Use Intention of Green Design Packaging
}

\author{
Chin-Hung Liu ${ }^{1} \&$ Ya-Hui $\mathrm{Wu}^{1}$ \\ ${ }^{1}$ Department of Business Administration, National Chin-Yi University of Technology, Taiwan \\ Correspondence: Chin-Hung Liu, Department of Business Administration, No.57, Sec.2, Zhongshan Rd., Taiping \\ Dist., Taichung City 41170, Taiwan. E-mail: chung1@ncut.edu.tw
}

Received: May 14, 2020

Accepted: June 4, 2020

Online Published: June 9, 2020

doi:10.5539/ijbm.v15n7p158

URL: https://doi.org/10.5539/ijbm.v15n7p158

\begin{abstract}
This study mainly investigates the relationships among VBN value-belief-norm (environmental moral obligation), technology acceptance model (perceived ease-of-use, perceived usefulness), and the intention to use designing sustainable packaging. A questionnaire survey was administered to consumers in various areas of Taiwan, and the responses were analyzed using statistical methods. The study results indicated the following: 1 . The significant and positive impacts existed among VBN value-belief-norm (environmental moral obligation), perceived ease-of-use, perceived usefulness, and the intention to use sustainable packaging, with the influence of biospheric value in VBN on the new environmental paradigm being the most significant. 2 . The consumers with various age and marital status had a significantly different perception on their intention to use designing sustainable packaging; the consumers with various age and occupation had a significantly different perception on their norms (environmental moral obligation), and when consumers purchased products that require packaging, whether they chose packaging with recyclable or reusable marks and functions had a significantly different perception on their VBN value-belief-norm, perceived ease-of-use, perceived usefulness, and intention to use designing sustainable packaging. Based on the analysis results above, we put forward suggestions regarding the recycling and reuse of resources, sustainable development technologies, and the cherishing of the ecological value of nature from the perspectives of consumers, companies, and the government.
\end{abstract}

Keywords: value-belief-norm theory, technology acceptance model, use intention of green design packaging

\section{Introduction}

In recent years, natural disasters, water shortages, air pollution, and energy crises have posed a serious threat to human life. Many environmental protection organizations have thus engaged in promoting the use of new energies and in promoting the public awareness of global warming as well as the need to protect oceans and primary forests (Yang, 2010). Incineration of waste produces not only exhaust gases but also slag, ash, and other volatile compounds, which have been recognized as the main sources of air pollution and today's smog problem. Therefore, how to reduce waste is an issue worth investigating. Plastic bags are widely used in modern life. If not properly addressed, the huge waste of plastic bags will become a thorny issue in the near future. Many packaging suppliers have been devoted to developing green design packaging to reduce material waste and minimize consumption of public resources. Considering the environmental impacts of their production, they adopt easily combustible, recycled or biodegradable materials to produce green design packaging materials. In fact, businesses across all industries can perform their social responsibilities by using green design packaging, which is delicately designed to reduce material waste and offer some additional functions to consumers (e.g. easy open ring design, standing bag design, and zipper bag design). Therefore, green design packaging has its important value.

The above-mentioned environmental actions, their value, and effects on human behavior can be explained using Stern's value-belief-norm (VBN) theory (Stern et al., 1999; Stern, 2000). There are three orientations or types of values relevant to environmental protection, including ecological value, egoistic value, and altruistic value. VBN theory posits that different value orientations lead to different factors affecting individual support for environmental movement. The rise of the New Environmental Paradigm (NEP) is linked to the growing public awareness of the fact that unlimited use of natural resources will do harm to the natural environment in multiple aspects and result in numerous environmental problems in the future. Lin (2017) found in a study of factors 
affecting the pro-environmental behaviors of eco-tourists that values have a significant effect on NEP. According to VBN theory, NEP is where individual beliefs lie. Chen (2016) used VBN theory to explore ecotourism behavior intention. Her findings indicate that NEP affects awareness of consequences, awareness of consequences affects ascribed responsibility, ascribed responsibility has a significant effect on personal norms, and personal norms are significantly related to ecotourism behavior intention. Chang (2018) explored the antecedent factors of green products usage among consumers and found that personal norms and perceived consumer effectiveness have a significantly positive effect on green purchase behavior intention and good citizen behavior intention. Consumers' environmental behaviors and purchase of products using green design packaging can help mitigate environmental impacts. With regard to technology acceptance model (TAM), perceived ease of use is defined as the degree to which one believes that by using a given innovation, one can achieve the expected outcome with relatively smaller effort. Venkatesh and Davis (2000) argued that perceived ease of use affects usage intention. To sum up, motivated by the above research background, this study attempts to explore factors affecting consumers' intention to use green design packaging based on VBN theory and TAM model.

\section{Literature Review}

\subsection{Green Product Packaging}

Through the promotion by World Business Council for Sustainable Development (WBCSD) in 1992, green consumption has become one of the focal issues of the 21 st century. With the rise of green consumption, environmental protection concepts have been incorporated into the production, design, packaging, and retail processes of products. However, in research and design of green products, most enterprises have focused on the selection of materials and the improvement of production processes and neglected consumers' needs in multiple aspects. As a result, the demand for green products in the consumer market is not as strong as expected (Chang, 2003). A number of businesses have taken environmental protection as their primary mission. They design and develop green products to attract attraction from consumers with green consciousness and take advantage of this green trend to enter the global market (Tu, 2002).

\subsubsection{The Design Concepts of Green Packaging}

The design of green packaging is based on 3Rs, which refer to reduce, reuse, and recycle (Hartmann, 2005). Burall (1994) mentioned that there should be no compromise on functionality in green designs and introduced the concept of "regeneration" as the fourth R. Regeneration is to reduce use of materials and energy in the production process. Scott (2007) stressed the importance of "Reeducation" in his book, suggesting that people must have the awareness that our habit of "disposing products after use" has turned our society into a wasteful society and also led to serious pollution in the environment. According to Tu (2013), with the development of environmental concepts, the 3R principles need to evolve to include "Regeneration". In other words, the design concepts of green packaging are now based on $4 \mathrm{R}$ principles. Tseng (2001) stated that green design should be based on a life cycle thinking and proposed a $5 \mathrm{R}$ concept which includes Reduce, Reuse, Recycle, Recovery, and Research. He stressed that designers should replace their design habits with a life cycle thinking that considers the end-of-life treatment of the product as early as in the design stage. Besides, Chang \& Yao (2008) provided a further explanation of environmental concepts and proposed the 6R principle which additionally includes Repair and Refuse (Lee, 2017; Lin, 2012). Table 1 provides a summary of the 3R, 4R, 5R, and 6R principles (Hartmann, 2005; Burall, 1994; Tu, 2013; Tseng, 1996; Chang \& Yao, 2008). To preserve the natural environment and develop better green packaging, designers can follow a number of basic rules, including minimize packaging, reduce use of materials, improve the strength of product structure, and recycle (Jarvenpaa et al., 1999).

\subsubsection{Organizations and Guidelines about Green Packaging}

In light of the continuous deterioration of environmental problems, the government in many countries has worked with local enterprises to develop policies, guidelines, and regulations to promote green packaging. They assist enterprises to acquire of international certifications for their product packaging, which can be a powerful marketing tool to promote trade and green consumption. The Restriction of Hazardous Substances Directive (RoHS), SGS grocery Lab, ISO 22000, and HACCP are some of the well-known systems that provide a guideline or validation for green packaging designs (Lee, 2017; SGS grocery laboratory, 2019; ISO, 2019).

\subsection{The Literature Addressing VBN Theory}

Theory of Planned Behavior (TPB), Norm-Activation theory (NAT), and VBN (Value-Belief-Norm) are the main theories applied in research of environmental behavior. VBN refers to Stern's theory about the relationship between values, beliefs, and norms (Stern et al., 1999; Stern, 2000). Values include ecological value, altruistic value, and egoistic value. They are one's values of the biosphere, other people, and the self. 
Beliefs are the foundation of the New Environmental Paradigm (NEP). According to Dunlap \& Van Liere (1978), NEP revolutionizes the mainstream social norms and proposes that human beings' ignorance of environmental protection during their pursuit of economic benefits has exacerbated numerous environmental problems, and it is necessary for us to seriously rethink our relationship with the natural environment. Hsieh (2009) showed the key ideas of NEP. The value of nature depends on whether we can discard human-centered, egoistic ideas and begin to appreciate the beauty of nature, embrace the existence of everything in the world, understand the rights and values of the natural environment, and pay attention to environmental protection to create a sustainable environment for our future generations (Yang, 2002). Gärling et al. (2003) pointed out in a study of TPB that behavioral intention represents one's intention to engage in pro-environmental behaviors. Their research model posits that pro-environmental behavior intention is affected by personal norms, ascribed responsibility, awareness of environmental consequences, awareness of altruistic consequences, and awareness of egoistic consequences. Schwartz (1992) indicated that if human's value of nature develops when the environment is being damaged, individuals will become aware of the environmental destruction they are facing. Such awareness is called "awareness of consequences". With such awareness, individuals may respond with pro-environmental behaviors, which are driven by consciousness of consequences. Besides, when people recognize human factors as the cause of the destruction, in order to mitigate or reverse the destruction, they will adopt behaviors that can redress the wrongs as a way to show their moral responsibility. This is a process called "ascribed responsibility". Spash et al. (2009) analyzed the motives behind willingness to pay for improving biodiversity in a water ecosystem. Due to the consideration of the effects of attitude, perceived behavioral control, and subjective norm as prescribed in TPB, they increased the significance and validity of the implications of the results and gained deeper insights into the noneconomic motives behind willingness to pay.

In addition to TPB, Norm-Activation Theory (NAT) (Schwartz, 1977; Wall et al., 2007) is also commonly applied in research of environmental behaviors. Wall et al. (2007) used commuters' choice of transportation means as an example to compare the effectiveness of TPB and NAT in explaining a consumers' pro-environmental behavior (reduced use of personal vehicles). They found that NAT is a more ideal theory for explaining commuters' reduced usage of personal vehicles. Stern et al. (1995) extended NAT to propose VNB theory. VBN proposes that one's egoistic value, altruistic value, and ecological value affect his or her beliefs, which are the foundation of NEP or Ecological Worldview, awareness of consequences, and ascribed responsibility and will further affect personal norms, driving the individual to adopt pro-environmental behavior (PEB). There are four major types of PEB: (1) environmental activism: highly committed behaviors such as participation in environmental protection activities; (2) non-activist behaviors in the public sphere: actions to support policy (monetary or non-monetary) to reduce the environmental impact of individual behaviors; (3) non-activist behaviors in the private sphere, such as making a purchase decision that contributes to environmental protection; and (4) organizational behaviors: behaviors that demonstrate the organization's commitment to environmental responsibility (Nordlund, 2009; Steg et al., 2005; Stern et al., 1995).

Based on the above literature, this study attempts to use Stern's VBN theory (Stern et al., 1999; Stern, 2000) as a foundation to create a model for exploring the key factors affecting consumers' usage of green design packaging. In this model, values are measured by ecological value, altruistic value, and egoistic value; beliefs are used to analyze the relationship among NEP, awareness of consequences, and ascribed responsibility; norms refer to the obligation to adopt pro-environmental behavior, that is, environmental moral obligation. Finally, the intention to use green design packaging is evaluated using items adapted from Lu's (2016) scale of green consumption intention.

\subsection{TAM (Technology Acceptance Model)}

Chang (2018) used TAM to explore the relationship among religious beliefs, subjective well-being, and behavioral intention. She developed a questionnaire based on the perceived ease of use and perceived usefulness dimensions of TAM. TAM has also been applied in the military to analyze the intentions to use an electronic service platform and usage of a mobile phone control APP (Kuo, 2018; Kao, 2017). Tsai (2018) explored the intentions to use mobile payment among consumers using a questionnaire developed based on the perceived usefulness and perceived ease of use dimensions in TAM. This study will also use TAM to analyze the effects of certain additional functions, such as easy open ring design, standing bag design, and zipper bag design, on consumers' usage of green design packaging. In other words, this study will investigate consumers' behavioral intention derived from their responses to perceived usefulness and perceived ease of use of these functions.

According to Davis (1989), Chang (2017), and Tsai (2018), this study will adopt the perceived usefulness and perceived ease of use dimensions in TAM as the main dimensions from TAM that affect consumers' intention to use green design packaging. 


\section{Research Structure and Method}

We examine the research question from consumers who have used existing product packaging with green design in this study. In recent years, the "pro-environmental behaviors" have been discussed by using VBN theory, and the use intention of green design packaging is also part of the "pro-environmental behaviors", which is used as an analysis and exploration purpose. Therefore, this research is based on the VBN theory proposed by Stern et al. (Stern et al., 1999; Stern, 2000) as the dimension of measuring the value-belief-norm of VBN in this study. In the value, it has the three dimensions including ecological value, altruistic value, and egoistic value; in the aspect of belief, it includes the connection between new environmental paradigm, awareness of consequence, and ascribed responsibility. In addition, norms adopt the sense of obligation to take pro-environmental actions. Finally, in assessment of use intention of green design packaging, we adopt the questionnaire of behavior intention of green consumption designed by $\mathrm{Lu}$ (2016) to develop a single dimension and measure use intention of green design packaging. Moreover, the combination of two dimensions of perceived ease of use and perceived usefulness of TAM (technology acceptance model) proposed by Davis (1989) and the above mentioned value, belief, and norm of VBN were used to explore the impact on use intention of green design packaging for pro-environmental behavior. In this study, we will also explore if perceptions of value, belief, and norm of VBN, perceived ease of use and perceived usefulness of TAM, and use intention of green design packaging vary by demographic variables. The research structure of the impacts among value, belief, and norm of VBN, perceived ease of use and perceived usefulness of TAM, and use intention of green design packaging, and consumers' perceptions on them is illustrated in Figure 1.

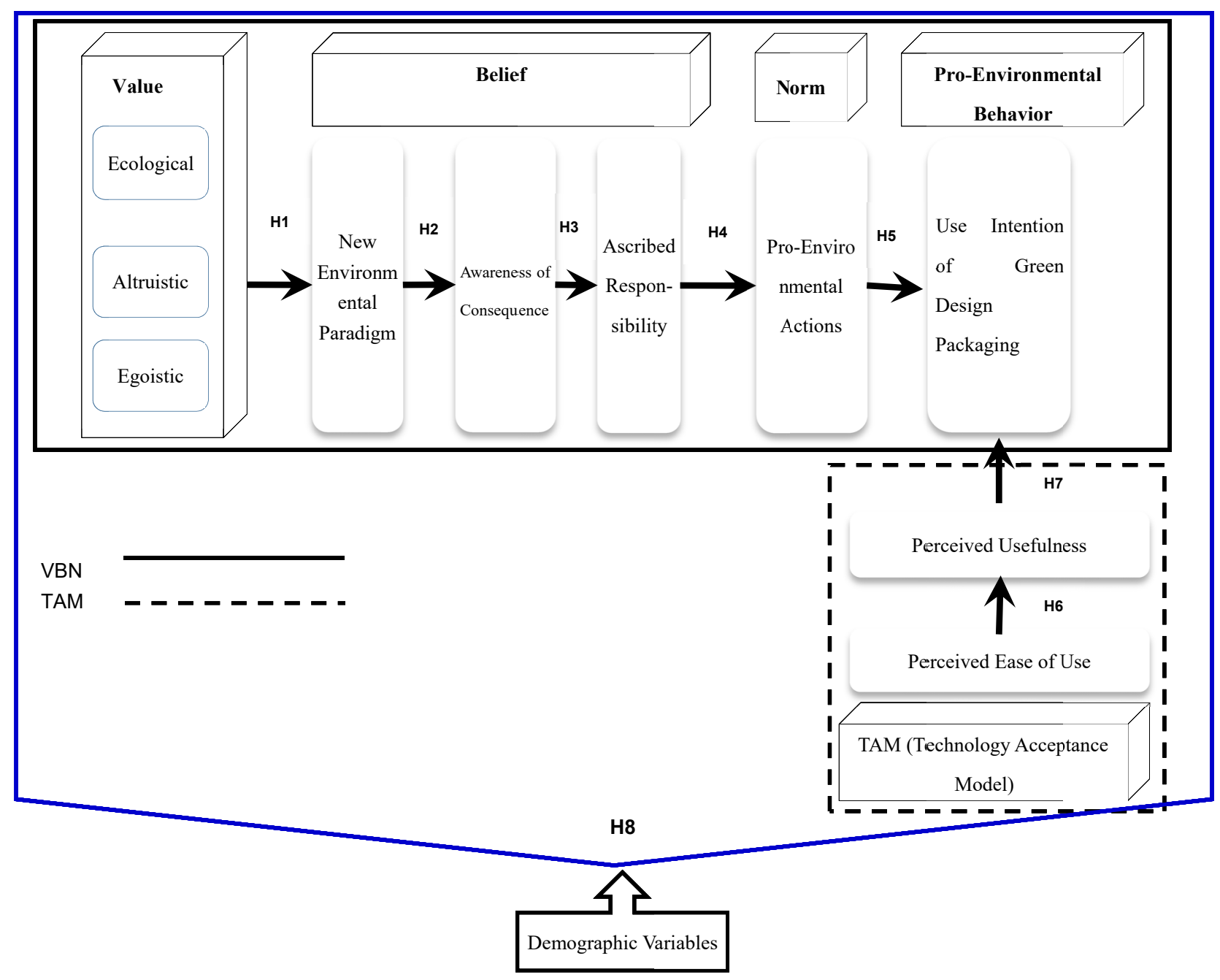

Figure 1. Research Structure 


\subsection{Research Hypothesis}

This study has developed the following research hypotheses based on the research purpose, literature review, and research framework, which are described separately as follows:

\subsubsection{The Impact of Value, Belief, and Norm (VBN) on Use Intention of Green Design Packaging}

The Value-Belief-Norm (VBN) theory was proposed by Stern et al. (1999) and Stern (2000). The dimensions of the value are ecological value, altruistic value, and egoistic value. The belief is to describe the relationship between new environmental paradigm, awareness of consequence, and ascribed responsibility. The norm is a sense of obligation to take pro-environmental actions. In addition, the dimensions of pro-environmental behavior include activism, nonactivist public-sphere behaviors, private-sphere behaviors, and behaviors in organizations.

The detailed related literature about VBN theory is described in literature review about value-belief-norm (VBN). Therefore, according to the literature review of the above scholars, it shows that ecological, altruistic, and egoistic values have a significant positive impact on new environmental paradigm in the belief. There are also significant positive effects among new environmental paradigm, awareness of consequence, and ascribed responsibility. Moreover, The ascribed responsibility of the belief has a significantly positive impact on the sense of obligation to take pro-environmental actions in personal norms. Finally, the sense of obligation to take pro-environmental actions of personal norms also has a significant positive impact on pro-environmental behaviors, that is, the value of VBN theory could promote belief, and enhance the sense of obligation to take pro-environmental actions which represents the sense of environmental morality in norms so as to improve the use intention of green design packaging. Therefore, the following research hypotheses are proposed in this study:

H1: Ecological, altruistic, and egoistic values have a significant positive impact on new environmental paradigm.

H2: New environmental paradigm has a significant positive impact on awareness of consequence.

H3: Awareness of consequence has a significant positive impact on ascribed responsibility.

H4: ascribed responsibility has a significant positive impact on sense of environmental morality.

H5: Sense of environmental morality has a significant positive impact on use intention of green design packaging.

3.1.2 The Impact of Perceived Ease of Use and Perceived Usefulness of TAM on Use Intention of Green Design Packaging

Davis (1989) developed the technology acceptance model (TAM) by exploring the impact of perceived ease of use and perceived usefulness on the acceptance degree of information technology. The results of this study found that perceived ease of use in the model would affect perceived usefulness and perceived usefulness also directly affects the intention to use. According to the literature review, we could infer that perceived ease of use has a significant positive impact on perceived usefulness, and perceived usefulness would also promote the use intention of green design packaging in the TAM. Therefore, the following research hypotheses are proposed in this study:

H6: Perceived ease of use has a significant positive impact on perceived usefulness.

H7: Perceived usefulness has a significant positive impact on use intention of green design packaging.

3.1.3 The Perception Differences of Demographic Variables for VBN (Value, Belief, and Norm; Sense of Environmental Morality), Perceived Ease of Use, Perceived Usefulness, and Use Intention of Green Design Packaging

Yang (2016) studied the influence of perceived value, subjective norms and attitudes on the intention to purchase original Line stickers in the rationality behavior theory, and the results of this study indicated that consumers of different genders and ages have significantly cognitive differences in perceived value and consumers who have different ages also have significantly cognitive differences in attitudes and purchase intention. Chu (2013) explored the preferences of green restaurants for different environmental beliefs for online users, and applied environmental beliefs to analyze the strong and weak clusters through the ecological paradigm scale. This research showed that different gender, age, marital status, education, income, occupation and place of residence have significant differences in perceptions of environmental beliefs. In addition, Sun (2018) researched the impact of consumers on the selection of airline services in tourism, and the results of this study found that demographic variables have significantly different effects on subjective norms, attitudes and perceived behavior control. Chen (2014) used an online travel agency as an example to explore the impact between the combination of planned behavior theory and technology acceptance modal on consumer purchase intentions, and the results of 
this research indicated that there are significantly differences in perceptions of marital status, occupation, current residence, average monthly income, experience using / browsing on travel websites, and frequency of visits / browsing travel websites per year on perceive ease of use, perceived usefulness, purchase attitude, e-satisfaction, subjective norms, perceived behavior control, e-service quality, and purchase intention. Moreover, Tseng (2016) integrated motivation, opportunity, ability, and technology acceptance model to study the influences between consumers' online, offline shopping, and brand preference. The results of this study revealed that consumers of different ages have significantly cognitive differences in perceived usefulness. Lo (2010) used technology acceptance models to explore the effects between ease of use of cognitive green buildings, usefulness of cognitive green buildings, subjective norm, usage attitude, and intention to use of green buildings, and the analysis results showed that there are significantly cognitive differences of different ages and educational levels of demographic variables in use intention of green buildings, ease of use of cognitive green buildings, use attitude, and subjective norm. There are also significant differences in perception of ease of use and usefulness of cognitive green buildings for consumers with different job tenures.

According to the above literature reviews, there are significant perception differences in VBN (value, belief, norm; sense of environmental morality), perceived ease of use, perceived usefulness, and use intention of green design packaging for different demographic variables. Therefore, the research hypothesis $\mathrm{H} 8$ is proposed as follows.

H8: There are significant differences in perceptions of demographic variables on VBN (value, belief, norm; sense of environmental morality), perceived ease of use, perceived usefulness, and use intention of green design packaging.

\subsection{Sampling Design}

The research questionnaire was issued in two stages: the first stage was the "pre-questionnaire", and it was surveyed anonymously from October 27, 2018 to November 3, 2018, and a total of 22 copies of the acceptable questionnaire were obtained. It was mainly to understand the response of questionnaire respondents and the clarity of the meaning of the questionnaire content, and to evaluate the appropriateness of the questionnaire. In addition, It was to improve unclear and inappropriate items of the questionnaire by reliability analysis; the second stage was the "formal questionnaire", the anonymous copies of the questionnaire were not only issued, but also the anonymous online questionnaires were used to survey. The periods of the survey were from November 10, 2018 to March 30, 2019. A total of 490 questionnaires were distributed to consumers in this study, and a total of 405 questionnaires were obtained. A total of 371 were acceptable responses, and the acceptable response rate was $75.71 \%$.

\section{Data Analysis and Results}

\subsection{Descriptive Statistical Analysis}

The sample composition is analyzed using descriptive statistics. The analysis results indicate that the sample consists of mainly females; unmarried respondents take a larger ratio than other groups; respondents aged 30 or below make up the largest age group; most respondents have a university/college degree, work in the manufacturing/industrial sectors, currently reside in central regions of Taiwan, and have a monthly income of $\$ 20,000$ or below. Besides, when making a purchase decision, most of them would prioritize products with a label showing that its packaging is recyclable or reusable.

\subsection{Reliability Analysis}

In this study, Cronbach's $\alpha$ value was used as the reliability measure, and the Cronbach's $\alpha$ coefficients and correlation coefficients between revised items and overall items were used to measure the internal consistency of the questionnaires. The coefficient value is higher between the above two, and it represents the measurement has more stable and consistent characteristics. The relative reliability value would also be higher. The overall reliability coefficient of this study was 0.976 by the reliability analysis. The reliability analysis of VBN showed that the overall reliability coefficient of Cronbach's $\alpha$ was 0.935 for the value, and the reliability coefficients of Cronbach's $\alpha$ of ecological, altruistic, and egoistic values were $0.913,0.836$, and 0.880 , respectively; the overall reliability coefficient of Cronbach's $\alpha$ was 0.935 for the belief, and the reliability coefficients of Cronbach's $\alpha$ of new environmental paradigm, awareness of consequence, and ascribed responsibility were $0.819,0.934$, and 0.862 , respectively; the overall reliability coefficient of Cronbach's $\alpha$ was 0.862 for the norm (sense of environmental morality); the overall reliability coefficient of Cronbach's $\alpha$ was 0.868 for the use intention of green design packaging. The reliability analysis indicated that the overall reliability coefficient of cronbach's $\alpha$ was 0.967 for the technology acceptance model, and the reliability coefficients of Cronbach's $\alpha$ of perceived ease 
of use and perceived usefulness were 0.938 and 0.950 respectively. The reliability values of this study were quite high because the reliability coefficients of the survey were all greater than 0.7 (Kerlinger, 1999). The correlation coefficients between revised items and overall items were greater than 0.5 , which means they meet the benchmark(Wu, 2015). The survey item "20. The natural environment is often harmed by plastic bags." was deleted due to the correlation coefficient of 0.251 between revised items and overall items less than 0.5 in this study.

\subsection{One Sample T-Test Analysis}

This study used the one sample t-test analysis to test null hypothesis $\mathrm{H}_{0}$ : the mean of population $(\mu) \leqq 3$, while alternative hypothesis $\mathrm{H1}: \mu>3$, which was utilized to analyze the survey of consumers for questionnaire items of VBN (value-belief-norm; sense of environmental morality), use intention of green design packaging, and TAM(technology acceptance model), and it showed to have the distribution situation of agreement or strong agreement.

\subsection{Correlation Analysis}

This study explores the correlation between the VBN (sense of environmental morality), use intention of green design packaging, and TAM through Pearson correlation analysis. In the value of VBN, under the significant level of $\alpha=0.01$, the $\mathrm{p}$ values among the value with belief, norm(sense of environmental morality), and use intention of green design packaging were 0.000 less than $\alpha=0.01$ by the correlation analysis, all of which had the significance. The correlation coefficients of them were $0.839,0.700$, and 0.685 respectively, which represents that there had medium and high positive correlations between them. Therefore, there were significantly positive correlations between the value with belief, norm(sense of environmental morality), and use intention of green design packaging, that was: The higher the agreement of consumer for the value, the higher the agreement of consumer for belief, norm(sense of environmental morality), and use intention of green design packaging. In the belief of VBN, under the significant level of $\alpha=0.01$, the $\mathrm{p}$ values among the belief with norm(sense of environmental morality) and use intention of green design packaging were 0.000 less than $\alpha=$ 0.01 , all of which had the significance. The correlation coefficients of them were 0.725 and 0.693 respectively, which represents that there had medium and high positive correlations between them. Therefore, there were significantly positive correlations between the belief with norm(sense of environmental morality) and use intention of green design packaging, which indicates: The higher the agreement of consumer for the belief, the higher the agreement of consumer for norm(sense of environmental morality), and use intention of green design packaging. In the norm(sense of environmental morality), under the significant level of $\alpha=0.01$, the $p$ value between the norm(sense of environmental morality) and use intention of green design packaging was 0.000 less than $\alpha=0.01$, which had the significance. The correlation coefficients of them was 0.810 , which represents that there had a high positive correlation between them. Therefore, there was a significantly positive correlation between the norm(sense of environmental morality) and use intention of green design packaging, which means: The higher the agreement of consumer for the norm(sense of environmental morality), the higher the agreement of consumer for use intention of green design packaging. Finally, in the TAM, under the significant level of $\alpha=$ 0.01 , the $p$ value between TAM and use intention of green design packaging was 0.000 less than $\alpha=0.01$, which had the significance. The correlation coefficients of them was 0.700 , which represents that there had a moderate positive correlation between them. Therefore, there was a significantly positive correlation between the TAM and use intention of green design packaging, which means: The higher the agreement of consumer for the TAM, the higher the agreement of consumer for use intention of green design packaging. To sum up, there were significantly positive correlations between the VBN (sense of environmental morality), use intention of green design packaging, and TAM.

\subsection{Factor Analysis}

\subsubsection{Factor Analysis of VBN-Value}

This research was to determine whether the value of VBN is suitable for factor analysis before performing a factor analysis of the value of VBN. The factor analysis was used to extract common factors between questionnaire items. The value of KMO sampling adequacy test was 0.946 , which was close to 1 . The approximate Chi-square distribution value of the Bartlett sphere test was 3703.010, the degree of freedom was 105 , and $p=0.000$ was significant, which indicates that it had the significance. The 15 survey items of the value of VBN had common factors, and they were suitable for factor analysis (Kaiser, 1974; Wu, 2015). The factor analysis used the principal component analysis method to extract common factors with eigenvalues greater than 1 , and then to perform rotation analysis by the Varimax method. The 15 survey items were extracted to the three dimensions through factor analysis, and the eigenvalues after the rotation were 4.146, 3.769, and 2.602, all 
greater than 1, indicating that the classification was appropriate and meaningful; the cumulated variance explained was $70.115 \%$, and it was greater than the benchmark of $60 \%$, indicating that the extraction dimension was reliable; the factor loadings were all greater than the benchmark of 0.4 , indicating that the survey items could effectively reflect the dimensions. The survey item after the factor analysis was different from the original dimension, such as the questionnaire item 6 (transferring from dimension: altruistic value to dimension: ecological value). The dimensions of each factor were extracted and illustrated in the following:

- Dimension one: it consists of items 1, 2, 3, 4, 5, and 6. According to VBN theory, these values reflect individual's perceptions of and care for life. They also stress that every existence in the ecological system has a value, rights, and the need to respect the living environment of other creatures and the interest of non-creatures. This dimension is named "Ecological value".

- Dimension two: it consists of items 7, 8, 9, and 10. According to VBN theory, these values suggest there is interdependence among all things in the natural environment. We will eventually suffer the consequences of the environmental destruction we have done. Therefore, it is our obligation to preserve and maintain the stability of the ecological system. This dimension is thus named "Altruistic value".

- Dimension three: it consists of items 11, 12,13,14, and 15. According to VBN theory, these values reflect an orientation to self-interest. With such orientation, one believes that the nature adapts on its own, and even if anything goes wrong, someone else will fix it. This dimension is named "Egoistic value".

\subsubsection{Factor Analysis of TAM}

This research was to determine whether the TAM is suitable for factor analysis before performing a factor analysis of the TAM. The factor analysis was used to extract common factors between questionnaire items. The value of KMO sampling adequacy test was 0.953 , which was close to 1 . The approximate Chi-square distribution value of the Bartlett sphere test was 4205.554 , the degree of freedom was 45 , and $p=0.000$ was significant, which indicates that it had the significance. The 10 survey items of the TAM had common factors, and they were suitable for factor analysis. The factor analysis used the principal component analysis method to extract common factors with eigenvalues greater than 1, and then to perform rotation analysis by the Varimax method. The 10 survey items were extracted to the two dimensions through factor analysis, and the eigenvalues after the rotation were 4.454 and 3.747 , all greater than 1, indicating that the classification was appropriate and meaningful; the cumulated variance explained was $82.014 \%$, and it was greater than the benchmark of $60 \%$, indicating that the extraction dimension was reliable; the factor loadings were all greater than the benchmark of 0.4 , indicating that the survey items could effectively reflect the dimensions. The survey items after the factor analysis were not different from the original dimensions. The dimensions of each factor were extracted and illustrated in the following:

- Dimension one: it consists of items 41, 42, 43, 44, and 45. According to TAM, this dimension measures the degree to which one believes that learning in a specific system is easy and free of effort. This dimension is named "Perceived ease of use".

- Dimension two: it consists of items 46, 47, 48, 49, and 50. According to TAM, this dimension measures the degree to which one believes that using a specific system can lead to higher efficiency and learning outcomes. This dimension is named "Perceived usefulness".

\subsection{Simple Linear and Multiple Regression Analyses}

4.6.1 Multiple Regression Analysis of the Effects of Ecological Value, Altruistic Value, and Egoistic Value (VBN-Value) on NEP (VBN-Belief)

The standardized regression equation was shown that new environment paradigm $=0.538 *$ ecological value + $0.142 *$ altruistic value $+0.233 *$ egoistic value through the multiple regression analysis. New environment paradigm was used as the dependent variable, and ecological, altruistic, and egoistic values of the VBN were utilized as independent variables. This study applied a multiple regression analysis to explore the impact of ecological, altruistic, and egoistic values on the new environment paradigm. This study performs a collinearity analysis in order to test the independence of each predictive variable. According to the analytical results, the values of VIF were $2.107,1.998$, and 2.230 less than 10 , which indicates the tolerances $(0.475,0.500,0.448)$ of the independent variables could meet the required benchmarks without collinearity problems. The independent variables of this study had no collinearity, which represents it could use multiple regression analysis. The analytical results showed that the explanation ability of variables of the overall model was 0.673 after $\mathrm{R}^{2}$ adjusted, indicating that the value of VBN could explain the variance of $67.3 \%$ of the new environmental paradigm. The F-value of $254.366(\mathrm{p}=0.000)$ in the overall measure of significance was significant and 
represented the regression effect with the statistical significance. In addition, the standardized coefficient $\beta$ of ecological value for the new environmental paradigm (NEP) was $0.538(t=12.469, p=0.000)$, the standardized coefficient $\beta$ of altruistic value for the new environmental paradigm was $0.142(t=3.373, p=0.001)$, and the standardized coefficient $\beta$ of egoistic value for the new environmental paradigm was $0.233(t=5.327, p=0.000)$. As shown in Table 1, NEP was most significantly affected by "Ecological value", followed by "Egoistic value" and "Altruistic value". The result of this research indicated that "Ecological value", "Altruistic value", and "Egoistic value" were all positively and significantly related to NEP. Therefore, H1 was supported.

Table 1. The effects of ecological value, altruistic value, and egoistic value (VBN-value) on NEP (VBN-belief)

\begin{tabular}{|c|c|c|c|c|c|c|}
\hline \multirow{2}{*}{ Model } & Standardized coefficients & \multirow{2}{*}{$\mathrm{R}^{2}$} & \multirow{2}{*}{ Adjusted $\mathrm{R}^{2}$} & \multirow{2}{*}{$\mathrm{t}$} & \multirow{2}{*}{ Significance } & \multirow{2}{*}{ VIF } \\
\hline & Beta distribution & & & & & \\
\hline (Constant) & & & & -0.818 & 0.414 & \\
\hline Ecological value & 0.538 & & & 12.469 & $0.000^{* * *}$ & 2.107 \\
\hline Altruistic value & 0.142 & 0.675 & 0.673 & 3.373 & $0.001^{* *}$ & 1.998 \\
\hline Egoistic value & 0.233 & & & 5.327 & $0.000^{* * *}$ & 2.230 \\
\hline
\end{tabular}

Note: dependent variable $=$ new environment paradigm $(\mathrm{NEP}) ;{ }^{* *} \mathrm{p} \leqq \alpha=0.01 ;{ }^{* * *} \mathrm{p} \leqq \alpha=0.001$.

\subsubsection{Multiple Regression Analysis of the Effect of NEP on Awareness of Consequence (VBN-Belief)}

The standardized regression equation was shown that awareness of consequence $=0.798 *$ NEP through the multiple regression analysis. Awareness of consequence was used as the dependent variable, and NEP was utilized as independent variables. This study applied a simple linear regression analysis to explore the impact of NEP on the awareness of consequence. The analytical results showed that the explanation ability of variables of the overall model was 0.636 after $\mathrm{R}^{2}$ adjusted, indicating that the NEP could explain the variance of $63.6 \%$ of the awareness of consequence. The F-value of $648.139(\mathrm{p}=0.000)$ in the overall measure of significance was significant and represented the regression effect with the statistical significance. Moreover, the standardized coefficient $\beta$ of new environmental paradigm (NEP) for the awareness of consequence was $0.798(t=25.459, p=$ 0.000 ). The result of this research indicated that "NEP" was positively and significantly related to awareness of consequence. Therefore, $\mathrm{H} 2$ was supported.

4.6.3 Multiple Regression Analysis of the Effect of Awareness of Consequence on Ascribed Responsibility (VBN-Belief)

The standardized regression equation was shown that ascribed responsibility $=0.608 *$ awareness of consequence through the multiple regression analysis. Ascribed Responsibility was used as the dependent variable, and awareness of consequence was utilized as independent variables. This study applied a simple linear regression analysis to explore the impact of awareness of consequence on the ascribed responsibility. The analytical results indicated that the explanation ability of variables of the overall model was 0.369 after $\mathrm{R}^{2}$ adjusted, indicating that the awareness of consequence could explain the variance of $36.9 \%$ of the ascribed responsibility. The F-value of $216.955(\mathrm{p}=0.000)$ in the overall measure of significance was significant and represented the regression effect with the statistical significance. Moreover, the standardized coefficient $\beta$ of awareness of consequence for the ascribed responsibility was $0.608(t=14.729, p=0.000)$. The result of this research indicated that "Awareness of consequence" was positively and significantly related to ascribed responsibility. Therefore, $\mathrm{H} 3$ was supported.

4.6.4 Multiple Regression Analysis of the Effect of Ascribed Responsibility (VBN-Belief) on Norm (Sense of Environmental Morality)

The standardized regression equation was shown that norm (sense of environmental morality) $=0.599 *$ ascribed responsibility through the multiple regression analysis. Norm was used as the dependent variable, and ascribed responsibility was utilized as independent variables. This study applied a simple linear regression analysis to explore the impact of ascribed responsibility on the norm. The analytical results indicated that the explanation ability of variables of the overall model was 0.357 after $\mathrm{R}^{2}$ adjusted, indicating that the ascribed responsibility could explain the variance of $36.9 \%$ of the norm. The F-value of $206.086(p=0.000)$ in the overall measure of significance was significant and represented the regression effect with the statistical significance. In addition, the standardized coefficient $\beta$ of ascribed responsibility for the norm was $0.599(t=14.356, p=0.000)$. The result of this research indicated that "Ascribed responsibility" was positively and significantly related to norm (sense of 
environmental morality). Therefore, $\mathrm{H} 4$ was supported.

4.6.5 Multiple Regression Analysis of the Effect of Norm (Sense of Environmental Morality) on Use Intention of Green Design Packaging

The standardized regression equation was shown that use intention of green design packaging $=0.810 *$ norm (sense of environmental morality) through the multiple regression analysis. Use intention of green design packaging was used as the dependent variable, and norm (sense of environmental morality) was utilized as independent variables. This study applied a simple linear regression analysis to explore the impact of norm on the use intention of green design packaging. The analytical results indicated that the explanation ability of variables of the overall model was 0.655 after $\mathrm{R}^{2}$ adjusted, indicating that the norm could explain the variance of $65.5 \%$ of the use intention of green design packaging. The F-value of $702.111(\mathrm{p}=0.000)$ in the overall measure of significance was significant and represented the regression effect with the statistical significance. In addition, the standardized coefficient $\beta$ of norm for the use intention of green design packaging was $0.810(t=26.497, p=$ 0.000 ). The result of this research indicated that "Norm (sense of environmental morality)" was positively and significantly related to use intention of green design packaging. Therefore, H5 was supported.

\subsubsection{Multiple Regression Analysis of the Effect of Perceived Ease of Use on Perceived Usefulness (TAM)}

The standardized regression equation was shown that perceived usefulness $=0.889^{*}$ perceived ease of use through the multiple regression analysis. Perceived usefulness was used as the dependent variable, and perceived ease of use was utilized as independent variables. This study applied a simple linear regression analysis to explore the impact of perceived ease of use on the perceived usefulness. The analytical results indicated that the explanation ability of variables of the overall model was 0.789 after $\mathrm{R}^{2}$ adjusted, indicating that the perceived ease of use could explain the variance of $78.9 \%$ of the perceived usefulness. The F-value of 1385.104 ( $p=0.000)$ in the overall measure of significance was significant and represented the regression effect with the statistical significance. Moreover, the standardized coefficient $\beta$ of perceived ease of use for the perceived usefulness was $0.889(\mathrm{t}=37.217, \mathrm{p}=0.000)$. The result of this research indicated that "Perceived ease of use" was positively and significantly related to perceived usefulness. Therefore, H6 was supported.

4.6.7 Multiple Regression Analysis of the Effect of Perceived Usefulness (TAM) on Use Intention of Green Design Packaging

The standardized regression equation was shown that use intention of green design packaging $=0.692 *$ perceived usefulness through the multiple regression analysis. Use intention of green design packaging was used as the dependent variable, and perceived usefulness was utilized as independent variables. This study applied a simple linear regression analysis to explore the impact of perceived usefulness on the use intention of green design packaging. The analytical results indicated that the explanation ability of variables of the overall model was 0.477 after $\mathrm{R}^{2}$ adjusted, indicating that the perceived usefulness could explain the variance of $47.7 \%$ of the use intention of green design packaging. The F-value of $338.322(\mathrm{p}=0.000)$ in the overall measure of significance was significant and represented the regression effect with the statistical significance. Moreover, the standardized coefficient $\beta$ of perceived usefulness for the use intention of green design packaging was $0.692(t=18.394, p=$ 0.000 ). The result of this research indicated that "Perceived usefulness" was positively and significantly related to use intention of green design packaging. Therefore, $\mathrm{H} 7$ was supported.

\subsection{Independent Sample T-Test Analysis}

This research explored and analyzed the difference between the sample means of two independent populations with the same variance.

4.7.1 The Difference in Perception of "Marital Status" on VBN (Value-Belief-Norm), Perceived Ease of Use, Perceived Usefulness, and Use Intention of Green Design Packaging

This study explored the difference in perception of "Marital status" on VBN (value-belief-norm), perceived ease of use, perceived usefulness, and use intention of green design packaging, and it applied Levene test analysis with the same population variances. The result of homogeneity test showed that the p-value of use intention of green design packaging was $0.05(\mathrm{t}=-1.963) \leqq \alpha=0.05$, which represents it had the significance. This suggested that "marital status" was a significant factor affecting consumers' perception of intention to use green design packaging. On average, married respondents scored significantly higher on this dimension than unmarried ones.

4.7.2 The Difference in Perception if "Whether Or Not to Choose Products with a Label Showing that Its Packaging Is Recyclable Or Reusable" on VBN (Value-Belief-Norm), Perceived Ease of Use, Perceived Usefulness, and Use Intention of Green Design Packaging 
This study explored the difference in perception of " Which packaging will be selected to have the label and function of recycling or reuse while purchasing packaging required for goods" on VBN (value-belief-norm), perceived ease of use, perceived usefulness, and use intention of green design packaging, and it utilized Levene test analysis with the same population variances. The test of homogeneity showed that there were significant differences in values, beliefs, norms, perceived ease of use, perceived usefulness, and use intention of green design packaging between different decisions to choose products with a label showing that its packaging is recyclable or reusable. "Consumers who buy products with that kind of label" scored significantly higher on the dimensions than "Consumers who may not necessarily or do not buy products with that kinds of label".

\subsection{One-Way Analysis of Variance}

This study used one-way analysis of variance to analyze whether there was a significant difference in perception between the dimensions of various factors in "demographic variables". It is necessary to use the homogeneity test of population variance to determine whether this analysis of variance violates of the homogeneity test of population variance before performing one-way analysis of variance. If the $p$ value does not have a significant level, and it means that the one-way analysis of variance is suitable. While the $\mathrm{p}$ value is confirmed to be significant by the one-way analysis of variance, and then the Scheffe method could be further used to perform multiple comparison analysis with more detailing. The results of this analysis found that the various ages of demographic variables had significant differences in perceptions of the norm (sense of environmental morality) and use intention of green design packaging. The analytical result by Scheffe's multiple comparison test revealed that consumers with aged 51 or older had a significantly higher agreement of the norm (sense of environmental morality) and use intention of green design packaging than that of those with aged 31-40. In addition, the consumers with different occupations also had significant differences in perceptions of the norm (sense of environmental morality) and use intention of green design packaging. According to Scheffe's multiple comparison test analysis, it was indicated that the consumers with various occupations as housekeeping/retired had a significantly higher agreement of the norm (sense of environmental morality) than that of those with the occupation as the student. The result of this research indicated that "Perceived usefulness" was positively and significantly related to use intention of green design packaging. Therefore, H8 was partially supported.

\section{Conclusions and Management Implications}

\subsection{Conclusions}

According to the results of this study, we could provide companies as the direction of production design considerations, which could increase consumers to use green design packaging and promote the implementation of green environmental protection policies issued by the government in order to achieve the goal of protecting the environment and resource reuse. The conclusions of this study are summarized as follows:

1) The results of simple linear regression and multiple regression analysis are described as follows

- The "ecological value", "altruistic value", and "egoistic value" of VBN-value all had significantly positive impacts on the new environmental paradigm. Moreover, the "ecological value" had the most significant impact on the new environmental paradigm.

- There were significantly positive influences between "new environment paradigm", "awareness of consequence ", and "ascribed responsibility " of VBN-belief.

- The VBN-norm (sense of environmental morality) had a significantly positive impact on use intention of green design packaging.

- The perceived ease of use had a significantly positive impact on perceived usefulness in the TAM, and the perceived usefulness also had a significantly positive impact on use intention of green design packaging.

2) The results of independent sample $t$ test analysis are illustrated as follows

- Consumers who had the various marital status would have significant differences in perception on the use intention of green design packaging, and the average agreement level of married consumers had significantly higher than that of unmarried them for use intention of green design packaging.

- There were significant differences in perception of "Whether or not to choose products with a label showing that its packaging is recyclable or reusable" on VBN (value-beliefs-norm), perceived ease of use, perceived usefulness, and use intention of green design packaging for consumers. In addition, consumers who buy products with that kind of label scored significantly higher on the dimensions than consumers who may not necessarily or do not buy products with that kinds of label.

3) The results shown by one-way analysis of variance are explained in the following: 
- In the age, consumers with the age of 51 years old or above had a significantly higher agreement level of the norm (sense of environmental morality) and use intention of green design packaging than that of those with the age of 31-40 years old.

- In the occupation, consumers with the occupations as housekeeping/retired had a significantly higher agreement level of the norm (sense of environmental morality) than that of those with the occupation as the student.

The summary of the above analytical results is shown that there were all significantly positive impacts among VBN (value-belief-norm), perceived ease of use, perceived usefulness, and use intention of green design packaging. Moreover, consumers with the different marital status and ages had significant differences in perceptions of the use intention of green design packaging, and those with the various ages and occupations had all significant differences in perceptions of the norm (sense of environmental morality), and those with "whether or not to choose products with a label showing that its packaging is recyclable or reusable" also had significant differences in perceptions of VBN (value-belief-norm), perceived ease of use, perceived usefulness, and use intention of green design packaging.

\subsection{Management Implications}

According to the impacts between VBN (value-belief-norm), perceived ease of use, perceived usefulness, and use intention of green design packaging and the perceptions of demographic variables on them, and management implications are as follows:

1) The following suggestions were proposed by this study because "ecological value" of VBN-value had the most significant effect on NEP:

- When shopping for needed products, consumers should avoid products using single-use packaging, buy products using recyclable or reused packaging instead to reduce resources depletion, and implement recycling to reduce the waste of packaging bags and the pollution it may cause.

- Enterprises should fulfil their social responsibility by minimizing the environmental impacts of their products. In their design of green packaging, they can follow the principles of reduce, recycle, and reuse.

- The government is advised to promote use of bioenergy, effectively implement its green policy, and encourage development of energy-saving materials to protect and preserve the ecological environment.

- Promoting recycling of resources and development of green designs across these three aspects, namely consumers, enterprises, and the government, can strengthen the ecological value of nature.

2) Analysis of differences in perceptions of demographic variables on various factors:

- The analysis by age shows that respondents aged 51 or above score significantly higher on norms (environmental moral obligations) and intention to use green design packaging than those aged 31-40. A plausible explanation is that consumers in the age group of 31-40 are in a stage of life where they have to work hard to make a living and develop their careers. They may thus be more indifferent to things in the surrounding environment. In their hectic life, convenience is the priority. As a result, they frequently buy products using single-use packaging and do not have much thought on green design when shopping for needed products. We suggest that enterprises make use of slogans and signs to remind their employees in this age group to implement waste sorting and resources recycling. Besides, enterprises can also organize environmental and energy-saving activities that allow participation of employees' families. In the activities, participants can use their creativity to make things from recycled packaging bags (e.g. weaving packaging bags into a hand bag, a basket or a bouquet of decorative flowers). Through education, they can increase the consciousness of environmental moral obligation and intention to use green design packing in this consumer group.

- The analysis by occupation shows that respondents in the "unemployed/retired" group score significantly higher on norms (environmental moral obligation) than those who are "students". This shows that students may be less informed of the characteristics of green design packaging on products on the market and there are limited sources for recycling green designing packaging. Therefore, the government can formulate policies to promote labeling of green design packaging. This can help students understand and tell green design packaging and apply the concept in daily life. The policy can also be promoted during student's campus service, allowing students to influence each other and gradually internalize the concept as a part of their habits. Eventually, there can be a higher sense of environmental moral obligation in students. 


\section{References}

Ajzen, I. (1991). The theory of planned behavior. Organizational Behavior and Human Decision Processes, 50, $179-211$.

Burall, P. (1994). Green-ness is good for you. Design, London, Design Council, 22-24.

Chang, C. C. (2018). An empirical study of the technology acceptance model in religious contexts - A case study in a religious foundation in Taiwan. Master Thesis, Department of Information Management, National Defense University, Taoyuan City, Taiwan.

Chang, C. Y. (2018). Exploring the antecedents of green product usage. Master Thesis, Department of Business Administration, Tamkang University, New Taipei City, Taiwan.

Chang, M. C. (2003). A study of successful commercial green products- A case study of the digital commercial product design. Master Thesis, Graduate Program of Design and Art College, Da-Yeh University, Changhua County, Taiwan.

Chang, T. C., \& Yao, K. F. (2008). Misplaced resources-The legend of general waste. Science Development, 421, 32-37.

Chen, B. C. (2018). Poison understands your life. Taipei City: Common Wealth Life Co., Ltd.

Chen, C. W. (2014). Study on the influence of the technology acceptance model and theory of planned behavior on purchase intention-Using online travel agency as an example. Master Thesis, Department of Business Administration, National Chin-Yi University of Technology, Taichung City, Taiwan.

Chen, P. Y. (2017). Using value-belief-norm theory to explore ecotourism behavior intention. Master Thesis, Department of Cultural Resources and Leisure Studies, National Taitung University, Taitung City, Taiwan.

Cheng, S. C. (2017). An application of the UTAUT model to explore the behavior intention of travel APP used by tourist. Master Thesis, Department of Tourism Management, Jin Wen University of Science \& Technology, New Taipei City, Taiwan.

Chu, M. L. (2013). A survey on how the internet users with different environmental belief choose the green restaurant they prefer. Master Thesis, Graduate program in Ecotourism, National University of Tainan, Tainan City, Taiwan.

Chung, H. C. (2015). Using technology acceptance model to explain why users adopt NFC mobile payment. Master Thesis, Department of Business Administration, National Kaohsiung University of Science and Technology, Kaohsiung City, Taiwan.

Cooper, P., Poe, G. L., \& Bateman, I. J. (2004). The structure of motivation for contingent values: A case study of lake water quality improvement. Ecological Economics, 50, 69-82.

Davis, F. D. (1989). Perceived usefulness, perceived ease of use, and user acceptance of information technology. MIS Quarterly, 13(3), 319-339.

Dietz, T., Fitzgerald, A., \& Shwom, R. (2005). Environmental values. Annual Review of Environmental Resources, 30, 335-372.

Dunlap, E. R., \& Van Liere, K. D. (1978). The new environmental paradigm: a proposed measuring instrument and preliminary results. The Journal of Environmental Education, 9, 10-19.

Gärling, T., Fujii, S., Garling, A., \& Jakobsson, C. (2003). Moderating effects of social value orientation on determinants of pro-environmental behaviour intention. Journal of Environmental Psychology, 23, 1-9.

Hartmann, P. (2005). Green branding effects on attitude: functional versus emotional positioning strategies. Marketing Intelligence \& Planning, 23(1), 9-29.

Hsieh, C. P. (2009). Value-Belief-Norm theory based training to promote the consequences and behaviors of marine environmental protection by students with mental deficiency from an elementary school of Keelung. Master Thesis, Institute of Education, National Taiwan Ocean University, Keelung City, Taiwan.

Huang, C. E. (1995). Analysis and teaching of environmental issues. Environmental Education Quarterly, 27, 20-33.

ISO International Standardization Organization. (2019). ISO 22000 for the supply chain of safe foods (September, 2005). Retrieved from https://www.iso.org/news/2005/09/Ref966.html

Jarvenpaa, S. L., Tractinsky, N., \& Vitale, M. (1999). Consumer trust in an internet store: A cross-cultural 
validation. Journal of Computer-Mediated Communication, 5, 1-33.

Kaiser, H. F. (1974). An idex of factorial simplicity. Psychometrika, 39(1), 31-36.

Kao, Y. Y. (2017). A study of APP for military mobile management based on technology acceptance model and information system success model - Taking an air force base for example. Master Thesis, Department of Information Management, National Pingtung University of Science and Technology, Pingtung County, Taiwan.

Kerlinger, F. N., \& Lee, H. B. (1999). Foundations of behavioral research (4th Ed.). New York, NY: Wadsworth Publishing.

Kuo, S. W. (2018). Using TAM and IDT for investigating users' behavior intention for electronic service platform: A case of management information system in National Defense University. Master Thesis, Department of Information Management, National Defense University, Taoyuan City, Taiwan.

Lee, K. Y. (2017). A study on the recent market development of green design-based on the application of packaging design. Journal of CAGST, 414-433.

Liao, S. J. (2011). An action research for enhancing elementary school students' attitude and behaviors of marine environmental protection by means of value-belief-norm theory. Master Thesis, Institute of Education, National Taiwan Ocean University, Keelung City, Taiwan.

Lin, C. T. (2012). The study of consumers purchasing behavior for green products and green packaging - A case study of greater Taipei area. Master Thesis, Department of Technology Management, Chung Hua University, Hsinchu City, Taiwan.

Lin, S. Y. (2017). A study on factors affecting pro-environmental behaviors of eco-tourists in Matsu national scenic area. Master Thesis, Department of Tourism, Ming Chuan University, Taipei City, Taiwan.

Lo, T. P. (2010). Using technology acceptance model to explore the behavior intention of employees toward green building - A case study of Tainan technology industrial park. Master Thesis, Executive Master of Business Administration, National Cheng Kung University, Tainan City, Taiwan.

$\mathrm{Lu}, \mathrm{P} . \mathrm{Y}$. (2016). The concept on the enterprise green responsibility and public consumption awareness among the new ecological paradigm. Master Thesis, Department of Public Relations and Advertising, Shih Hsin University, Taipei City, Taiwan.

Nordlund, A. M. (2009). Values, attitudes, and norms. Future Forests Working Report, Umeå University.

Ojea, E., \& Loureiro, M. L. (2007). Altruistic, egoistic and biospheric values in willingness to pay (WTP) for wildlife. Ecological Economics, 63, 807-814.

Schwartz, S. H. (1977). Normative influences on altruism. Journal of Advances in Experimental Social Psychology, 10, 221-279.

Schwartz, S. H. (1992). Universals in the content and structure of values: Theory and empirical tests in 20 countries. Advances in Experimental Social Psychology, 25, 1-65. New York: Academic Press.

Scott, N. (2007). Reduce, recycle, and refuse: By doing so, garbage becomes green gold. Taipei: Sun Moon Culture Publishing.

SGS Grocery Laboratory. (2019). Food utensils, containers, packaging materials testing services, retrieved from http://twap.sgs.com/sgssip/hardlineservice.aspx\#section01

Spash, C., Urama, K., Burton, R., Kenyon, W., Shannon, P., \& Hill, G. (2009). Motives behind willingness to pay for improving biodiversity in a water ecosystem: Economics, ethics and social psychology. Ecological Economics, 68, 955-964.

Steg, L., Dreijerink, L., \& Abrahamse, W. (2005). Factors influencing the acceptability of energy policies: A test of VBN theory. Journal of Environmental Psychology, 25, 415-425.

Stern, P. (2000). Toward a coherent theory of environmentally significant behavior. Journal of Social Issues, $56(3), 407-424$.

Stern, P. C., Dietz, T., Abel, T., Guagnano, G. A., \& Kalof, L. (1999). A value-belief-norm theory of support for social movements: The case of environmentalism. Human Ecology Review, 6(2), 81-97.

Stern, P. C., Dietz, T., Guagnano, G. A., \& Kalof, L. (1995). Values, beliefs and pro-environmental action: Attitude formation toward emergent attitude objects. Journal of Applied Social Psychology, 25, 1611-1636. 
$\mathrm{Su}, \mathrm{M}$. W. (2014). Use value-faith-regulation theory is to explore the intention of electric buses. Master Thesis, Graduate Institute of International Business and Intercultural Management, Wenzao Ursuline University of Languages, Kaohsiung City, Taiwan.

Sun, C.-K. (2018). Air empirical study on customers' purchase intentions of airlines. Ph.D. dissertation, Department of Business Administration, National Chiayi University, Chiayi City, Taiwan.

Svanes, E., Vold, M., Møller, H., Pettersen, M. K., Larsen, H., \& Hanssen, O. J. (2012). Sustainable packaging design: A holistic methodology for 50 packaging design. Packaging Technology and Science, 23, 161-175.

Tsai, W.-T. (2018). Study of the application of technology acceptance model to the financial consumer action mobile payment. Master Thesis, Department of Information and Learning Technology, National Tainan University, Tainan City, Taiwan.

Tseng, C. C. (2016). A study of the relationship between O2O shopping and brand preference: An integrated perspective of MOA and TAM. Master Thesis, Department of Business Administration, National Taipei University, Taipei City, Taiwan.

Tseng, H. S. (1996). The concept of packaging design for the green age (Part 1). Taipei: Trade Weekly, 1706, 4-8.

Tseng, H. S. (2001). Green packaging design. Taipei: Taiwan Packaging Industry Magazine.

Tu, J. C. (2002). Product sustainable design-Green design and practice. Taipei: Asia Pacific Press.

Tu, J. C. (2013). Grasp the power of sustainability: Green innovation and market business opportunities. Taiwan: Small and Medium Enterprise Administration, Ministry of Economic Affairs.

Tu, J. C., \& Huang, Y. Q. (2015). Rejuvenate with craft and design. Taiwan Crafts, 58, 18-23.

Venkatesh \& Davis. (2000). A theoretical extension of the technology acceptance model: Four longitudinal studies. Management Science, 46(2), 186-204.

Verghese, K., \& Lewis, H. (2013). Environmental innovation in industrial packaging: A supply chain approach. International Journal of Production Research, 45, 4381-4401.

Wall, R., Devine-Wright, P., \& Mill, G. A. (2007). Comparing and combining theories to explain pro-environmental intentions-The case of commuting mode choice. Journal of Environment and Behavior, 39(6), 731-753.

Wu, W. Y. (2019). Business research methods. Taipei City: Hwa Tai Publishing Co., Ltd.

Yang, G. C. (2002). Environmental ethics-The ultimate goal of environmental education. Chinese Journal of Environmental Education, 1, 1-11.

Yang, M. H. (2010). One hundred knowledge about environmental protection. Taipei City: Station Culture.

Yang, S. T. (2016). A study of the theory of reasoned action on Line stickers purchase intention. Master Thesis, Department of Leisure Services Management, Chaoyang University of Technology, Taichung City, Taiwan.

Yen, H. Y. (2015). The effects of technology acceptance model, mobile advertising on O2O purchase intentionUsing UNIQLO as an example. Master Thesis, Department of International Business, Ming Chuan University, Taipei City, Taiwan.

Zaltman, G., \& Burger, P. C. (1975). Marketing research: Fundamentals \& dynamics. Stanford: International Thomson Publishing.

Zhou, Q. L. (2005). Introduction to logistics. Beijing: Tsinghua University Press.

\section{Copyrights}

Copyright for this article is retained by the author(s), with first publication rights granted to the journal.

This is an open-access article distributed under the terms and conditions of the Creative Commons Attribution license (http://creativecommons.org/licenses/by/4.0/). 